\title{
Analysis on the test results and the effect of autonomous learning in College English Network Course
}

\author{
LI Hongji ${ }^{1, a}$ \\ ${ }^{1}$ Jilin Business and Technology College, Changchun 130000, China \\ aemail: lihongji@163.com
}

Keywords: English curriculum; curriculum test; performance correlation

\begin{abstract}
The establishment of any system has its principles, and the establishment of the training system of College Students' English autonomous learning ability must have the principle of the design. In the process of establishment of College Students' English autonomous learning ability cultivation system, we need to follow a number of principles, in order to make the establishment of the evaluation system is more reasonable, more conducive to the cultivation of learner autonomy in College English teaching, in order to assure the quality required to achieve educational goals of the learning process. In this paper, we mainly introduce the design principles of the training evaluation system of College English autonomous learning ability.
\end{abstract}

\section{Introduction}

In the course of teaching, the evaluation process of learning must not be ignored. College English autonomous learning ability training evaluation system should be an effective part of the teaching plan. The teaching plan developed by the teachers should provide learners and learners with the opportunity to obtain and use some information, thus making them more able to achieve their teaching goals. At the same time, the teaching plan must also to respond flexibly to new ideas and techniques, including some strategy, to ensure that the learners to understand their learning goals, and suitable for them to learn the evaluation standard. Learners how to get feedback, how to participate in the evaluation of their learning and how to achieve further development should be included in the plan.

From the teaching process, the teacher's teaching objectives should be clear and specific, in line with the requirements of teaching materials and the actual requirements of students. Teacher's teaching content should be scientific, the capacity, the difficulty degree should be suitable, manifests the discipline knowledge integration, and from the student actual and the teaching request, the internalization and the activation teaching material. Teachers' teaching methods should be flexible, innovative, and should be appropriate to use modern educational technology tools. College English autonomous learning ability training evaluation system for students in the classroom to give timely feedback and correction, and guide students to evaluate each other and self evaluation. Through the feedback of the evaluation system, teachers should timely adjustment of teaching plan, to achieve the goal of teaching, achieve the expected teaching effect, let the students moral education, intellectual education, and will get the development, and ultimately enhance their comprehensive quality.

\section{Guidance}

Autonomous learning refers to learners consciously according to their specific situation, through the establishment of learning objectives formulated study plan, choose the way of learning, monitoring the learning process and self evaluation of the teaching effect way for self learning. In the process of cultivating students' autonomous learning ability in College English learning, the guiding of learning evaluation system should not be ignored.

Through the establishment of independent learning ability training evaluation system, to further understand the student's learning situation and the effect of learning, to see whether it has reached the goal of teaching plan. In the process of evaluation of student learning, we can use evaluation system, timely find students learning process, to correct the deficiencies of the study, to guide 
students to establish correct learning objectives, let students understand and master them with what method to learn what, and learning effect. Thus, students can better grasp the learning methods, timely according to the results of the evaluation of learning, adjust their own learning, so that learning to achieve the best results.

\section{Incentive}

College English learning is a gradual process, in the study of high school students to spend a lot of time to recite the word, recite the text, to master the structure of the sentence. This is a long process of accumulation, in this long learning process, the students to overcome the difficulties of all kinds of memory, repeat the study will inevitably make the students feel boring, boring. How to cultivate students' lasting interest in learning English, stimulate the students' learning desire and confidence, become a problem in front of every English teacher.

The establishment of the evaluation system of College English autonomous learning ability training can stimulate students' learning and help students to effectively control their own learning, which is a great guarantee to stimulate students' interest in learning English. This evaluation system to give up the past, "a paper" evaluation method, no longer let the students because of a poor performance, and the loss of interest in English learning. Through the emphasis on the students' learning process showed the interest, attitude, class participation and classroom performance to give a positive, encouraging evaluation, in order to improve the enthusiasm of students learning. In the process of learning English, students should be timely, appropriate evaluation and encouragement. Teachers should see every progress of the students, and according to the actual situation of the students to encourage evaluation. On the lack of confidence of students, teachers should be good at discovering and using their flash point, timely recognition and encouragement of students, in order to increase the students' self-confidence, thus stimulating the students' learning interest.

Using built in to incentive for the principle of learning evaluation system can protect the student's self-esteem, enhance students' self-confidence, the students can strengthen the role of intrinsic motivation, help to learn effective regulation and control their own learning process, so that students no longer afraid of learning English, "grind" to "learn"; students learning English to mobilize the enthusiasm and creativity, stimulate the learning potential of each student and better learning English[1].

\section{Test and performance characteristics}

The important content of the modern education thought is the establishment of the main body of the students and the development of the subjectivity, which is the key to improve the overall quality of students and to cultivate their innovative ability. In the whole process of education, students are always the main body. Both the evaluation of teachers and parents evaluation, for students learning effects will finally need through students' self evaluation mechanism, make their students on the evaluation of the identification and internalization, of their own produce correct, objective, active understanding to the evaluation of the transformed for the motivation to learn, and ultimately to to promote their science learning. Therefore, it is necessary for students to self evaluate their continuous development.

In English teaching, most understand students' learning, I am a student, so it should be to enable students to participate in the evaluation, take to students as the main body, teachers and students together to participate in the evaluation form, make the students have the right to their classmates and study evaluation. Let the students participate in the learning evaluation, self-evaluation and mutual evaluation, both with full respect for the dominant position of students, and students are encouraged to form their own unique quality and style, to arouse the enthusiasm and initiative of the students in learning English and improve the students' interest in learning English has an important role. First, evaluation in the students on their own or companion of English learning process, you can give full play to the subjective initiative, independent learning and thinking from the middle school, enhanced the students to have a correct understanding and evaluation of their own and others, can strengthen the students' subject consciousness. Secondly, let the students participate in the evaluation of English learning, can reduce the one-sided evaluation of English teachers. As a 
result of the combination of students self evaluation and mutual evaluation, teacher evaluation, which can ensure the openness and fairness of the evaluation results of College English learning, it is easy for students to accept. Again, to students as the main body of English learning assessment changed the past "to the students how to", "don't allow students to" and "against the students how to" confine students teaching management mode, pay attention to cultivate the students ability of observation, analysis and problem solving ability, information collection ability, experimental operation ability, expression ability, and so on, which to enhance the innovation ability of students benefit greatly[2].

The diagnostic principle of education evaluation is to point out that the evaluation should have a practical function, which can be used to diagnose the deficiency of practical education and to improve the effectiveness of the work. The educational evaluation activities and the general scientific theories are different, and the practice is very strong. Evaluation activities if you can not help the evaluation of the object to find work or learning problems, and to improve the value of their help, then this evaluation is to take the form, will not be popular, will not be accepted.

To carry out the diagnostic principle of education evaluation, one is to require that the evaluation should be made clear. In view of the practical problems, make full use of the guiding role of the evaluation, and promote the solution of practical problems. For example, in the middle school, the one-sided pursuit of graduation rates, teachers' teaching focus only on the imparting of knowledge, the pursuit of pure fraction of students, evaluation of school education, the new curriculum reform requires the teachers teaching evaluation and student evaluation can not effectively promote to solve these problems. So, evaluation of the lost practical utility. Two is to require the evaluation process of the subject and object mutual communication, timely feedback and evaluation of information, and help to solve the problem of evaluation objects, so that it is conducive to the promotion of evaluation objects active participation in evaluation, and consciously improve the work. Diagnosis is conducive to the early diagnosis of educational activities in accordance with the educational objectives of its feasibility, lay the foundation for further development.

The development principle refers to the goal of educational evaluation, which is to seek the development of the relationship between the subject and object of education, especially the positive development. Although an important feature of the educational evaluation is pointed out that the consequences of education value in practice in the process of movement, but the essence of educational evaluation is to foresee the future. It is pointed out that the development of the subject of the value of the subject of education, as well as the value of the object of education in the role of practice, can provide the new features.

At present, China's education evaluation in the promotion of "to promote construction", is based on this principle. The developmental function of educational evaluation is intrinsic to the whole space-time consciousness, which is not possible to have the development function. The principle of effectiveness of education evaluation is also related to the overall sense of time and space, but it is a focus on the evaluation of the practical significance of education. The development principle of the educational evaluation and the whole time and space consciousness relation, then focus on the evaluation of the future education development. The emphasis of both is different. To adhere to the principle of development of educational evaluation, it is necessary to study the development of the subject of educational value. Only in this way can we truly develop the educational evaluation. It is not only the sign of the scientific evaluation of education, but also the requirement of the scientific evaluation of education to exert the function and function correctly[3].

\section{Evaluation of objective freedom}

Constructivism claims that learners can only explain the information in the context of their own experiences, which is something else. As the designer of objectivism, we try to will be unique to the reality mapping in learners, however, learners must ultimately explain our message in his experiences and knowledge background, and construction related to their needs, background and interest in interpretation. Therefore, constructivism holds that, instead of going to will the structure mapping from an external reality on learners, still be inferior to help students to construct about the 
world outside, meaningful, with characterization of the concept of function.

According to the hypothesis of constructivism, the results of the study are constructed by individuals, then how should we evaluate the constructivist learning structure? Which criteria can be applied to evaluate the significance of learning in complex cognitive environments? Jonathan proposed the following evaluation criteria, only as a starting point for the idea of the evaluation method from the perspective of constructivism. These criteria express the integrated components of most constructivist learning definitions.

A significant impact of Constructivism on learning evaluation is the evaluation of the goals that should be compared to the free. The purpose of evaluation and construction of objective freedom is to overcome the bias caused by the evaluation of special design objectives. This evaluation of the view that, if not based on a predetermined goal to provide information to the evaluation staff, then the evaluation will be more objective. Therefore, it is suggested that the evaluation should not be evaluated according to the goal, but to use the demand evaluation method to determine the goal of education. He believes that the need to be confirmed in order to provide the most objective evaluation criteria for any process results.

It is obvious that the learning outcomes of Constructivism can be judged by the evaluation method of the freedom of the target. If a specific goal is known before the learning process starts, then the learning process and the evaluation will be biased. To provide a reference standard for the evaluation of teaching. This means that learning can be driven by teaching, whereas teaching is controlled by the student's learning activities. Standard reference teaching and evaluation are the objective construction of the prototype, so it is not suitable for the evaluation method of the constructivism environment.

It is obvious that the method used to evaluate the results of the constructivist learning system must be the goal of freedom. However, if constructivism is an accepted learning principle, the method of evaluating the results of the study should be re conceived. It is not enough to say that the evaluation should be the aim of freedom. The complexity of the cognitive complexity that we must have in order to evaluate the methodology of the evaluation of the results of constructivism.

An important criterion for the reconstruction of schools is to gather the education on the real task. Real task refers to those with the real world and utilities related tasks, they are for those tasks across the curriculum integration, they provide a appropriate level of complexity and allow students to choose the appropriate level of difficulty or tolerance range. We can't be an expert in every field of content. According to this belief, task and content analysis should pay less attention to the identification and description of the individual and the best learning order, and should pay more attention to the task of choosing both the meaning and the application of constructivism. Should be identified in the order and the concept of choice, they expressed a different view and can be expressed as a choice of evaluation needs[4].

Almost every definition of Constructivism puts forward the construction of knowledge rather than the representation of knowledge, that is, the learner must actively participate in the establishment of the knowledge structure. This means that, as an evaluation, we should pay attention to the results of the study, because it reflects the intellectual process of knowledge construction. Knowledge construction must have advanced thinking, which is very clear. Therefore, to construct the evaluation results of environmentalism should include such as Merrill) term "found evaluation level, Gagne Gagne cognitive level and bloom in terms of the comprehensive level of advanced thinking. We can hope for the students to create new learning objectives and methods. Obviously, the solution to the problem is a reasonable result. Disputes, namely, development and maintenance of their own specific position should also be appropriate to learn the results. The main criteria for evaluating the results of each knowledge construct should be unique (originality). In addition, appendages of the evaluation criteria is not the goal of free evaluation, but the construction of evaluation criteria, the proposed evaluation who must use assessment for learning the screen first, and just focus on advanced skills.

If we assume that reality has to rely on human psychological activity, then the meaning is determined by the individual's psychological processes, and these psychological processes are based 
on perception, which are generated in the experience. It can be seen that we should evaluate the construction of experience, rather than the external behavior and its results. This means that constructivist learning evaluation should be the process of knowledge acquisition, and not just the result. From the perspective of constructivism[5], it is more important to evaluate learners how to construct knowledge construction than to evaluate the results. This shows that effective evaluation must be integrated with the teaching, which is a part of the teaching process.

\section{Conclusion}

Because of constructivism, learning is supported by a rich background, so designers and reviewers must take into account the background of the study. The learning environment of constructivism is most effective for advanced knowledge acquisition. Jonathan described the three stages of knowledge acquisition: the guiding stage, the advanced stage and the expert stage. Guided learning occurs when students have little or no prior knowledge about a particular skill or content area. It expresses the initial stage of schema collection and integration. The second stage of knowledge construction is the access to advanced knowledge, which is an intermediate stage of learning. Learners must acquire advanced knowledge in order to solve complicated problems and rely on the background or field. Specialized knowledge is the final stage of knowledge acquisition. We know that the experts have the internal cohesion, with a wealth of knowledge structure, and the way they characterize the problem is not the same.

\section{References}

[1] Zhuang Zhixiang, Huang Wei, Wang Le. Current situation and Prospect of [J]. foreign language teaching multimedia foreign language teaching in China, 2007 (1).

[2] Li Xiaoxiang. Stage of College English teaching reform of achievements and thinking [C]. Chengdu: University, Ministry of education, English teaching reform expert tour. 2006. 10.

[3] Wang Xiaolei. Study [J]. Heilongjiang science and technology information of independent research students under the network environment, 2008 (1): 142.

[4] Xiao Liangrong, Yu really. On the opportunities and challenges and [J]. language of computer network technology brings to the teaching of College English, 2002.

[5] Shen Yinzhen. Multi culture and Contemporary English teaching [M]. Hangzhou: Zhejiang University press, 2006, (3): 92. 